\title{
Understanding Performance Management in Primary Care
}

DOI:

10.1108/IJHCQA-10-2015-0128

\section{Document Version}

Accepted author manuscript

Link to publication record in Manchester Research Explorer

\section{Citation for published version (APA):}

Boaden, R., \& Rogan, L. (2017). Understanding Performance Management in Primary Care. International Journal of Health Care Quality Assurance, 30(1), 4-15. https://doi.org/10.1108/IJHCQA-10-2015-0128

\section{Published in:}

International Journal of Health Care Quality Assurance

\section{Citing this paper}

Please note that where the full-text provided on Manchester Research Explorer is the Author Accepted Manuscript or Proof version this may differ from the final Published version. If citing, it is advised that you check and use the publisher's definitive version.

\section{General rights}

Copyright and moral rights for the publications made accessible in the Research Explorer are retained by the authors and/or other copyright owners and it is a condition of accessing publications that users recognise and abide by the legal requirements associated with these rights.

\section{Takedown policy}

If you believe that this document breaches copyright please refer to the University of Manchester's Takedown Procedures [http://man.ac.uk/04Y6Bo] or contact uml.scholarlycommunications@manchester.ac.uk providing relevant details, so we can investigate your claim.

\section{OPEN ACCESS}




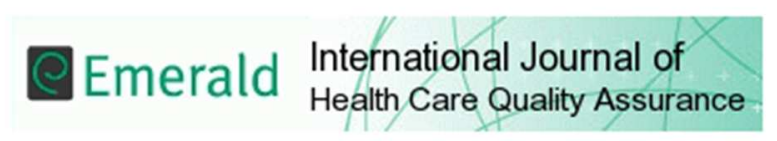

\section{Understanding Performance Management in Primary Care}

\begin{tabular}{|r|l|}
\hline Journal: & International Journal of Health Care Quality Assurance \\
\hline Manuscript ID & IJHCQA-10-2015-0128.R2 \\
\hline Manuscript Type: & Original Article \\
\hline Keywords: & $\begin{array}{l}\text { Accountability, performance, Management, principal-agent theory, goal } \\
\text { alignment, primary care }\end{array}$ \\
\hline \multicolumn{2}{|l}{} \\
\hline
\end{tabular}

\section{SCHOLARONE $^{\text {m }}$ \\ Manuscripts}




\section{Understanding performance management in primary care}

Author 1: Lisa Rogan, BSc(Hons), MA, PhD, Head of Medicines Commissioning, East Lancashire Clinical Commissioning Group (CCG), Nelson, Lancashire, UK, 07985 186240, Email: lisa.rogan@eastlancsccg.nhs.uk

Author 2: Ruth Boaden, MA, MSc, PhD, Director NIHR Collaboration for Leadership in Applied Health Research and Care (CLAHRC) Greater Manchester and Professor, Alliance Manchester Business School, Manchester, UK, 0161306 3436, Email: ruth.boaden@manchester.ac.uk

\section{Corresponding Author: Lisa Rogan}

Email: lisa.rogan@eastlancsccg.nhs.uk

\section{Structured Abstract}

Purpose: Principal-agent theory has been used to understand relationships among different professional groups and explain performance management between organisations, but is rarely used for primary care research. This article explores whether principal-agent theory can be used attain a better primary care performance management understanding.

Design/Methodology/Approach: Purposive sampling was used to identify general practices in north west England. Interviews were carried out with directors, managers and clinicians in commissioning and regional performance management organisations and within general practices. Data analysed using matrix analysis techniques were used to produce a performance management case study.

Findings: There are various principal-agent framework elements that can be applied in primary care. Goal alignment is relevant, but can only be achieved through clear, strategic direction and consistently interpreting objectives at all levels. There is confusion between performance measurement and performance management and a tendency to focus on things that are easy to measure whilst omitting care aspects that are more difficult to capture. Appropriate incentives, good communication, clinical engagement, ownership and trust affect the degree to which information asymmetry is overcome and goal alignment achieved. Achieving the right balance between accountability and clinical autonomy is important to ensure governance and financial balance without stifling innovation.

Originality/Value: The principal-agent theoretical framework can be used to better understand performance management in primary care; although it is likely that only partial goal alignment will be achieved, dependent on alignment among of several factors.

Keywords: Performance; Management; Principal-agent theory; Goal alignment; Primary care; Mangers; Clinicians.

\section{Article Classification: Case Study}

Received: $19^{\text {th }}$ Oct 2015

Revised:

Accepted:

\section{Introduction}

Although principal-agent theory has been used to understand relationships among different professional groups and explain contractual arrangements and performance management between organisations, principal-agent theory's use in primary care research is limited. Performance management is a major feature of managing healthcare in a publicly-funded 
system, and is used in particular to provide assurance to commissioning organisations regarding accountability, safety, efficiency and quality. The growing emphasis on performance management in primary care highlights the importance of understanding and exploring this concept.

There is an increasing emphasis on improving public services effectiveness using private sector principles (Radnor and McGuire, 2004) where managers are under pressure to demonstrate service quality and value through improved customer focus, flexibility, innovation and cost (Neely, 1999). There is evidence to suggest that where performance measurement systems have been adopted by managers as an approach to management, performance tends to be better than those where such systems have not been used (Lingle and Schiemann, 1996; Carmen and Fredericks, 2010).

Within public sector healthcare systems, performance measurement role, including using clinical indicators, has changed from being a minor component in healthcare management to one where the demands for greater accountability, safety, efficiency and quality have accentuated measurement and reporting. Despite the fact that performance measures are now widely used within the public sector, there remains little evidence about their usefulness and whether managers actually achieve goals set by policy-makers (Propper and Wilson, 2003). There is a drive to develop more performance indicators, although there has been little evidence that they have had a positive effect on decision making, improved health services, or health outcomes (Adair et al., 2003) or have been able to demonstrate their overall effect or value for money (Sheldon, 2005). However, in complex organisations and systems such as the NHS, it seems likely that multiple performance management systems (PMSs) will be required to achieve overall success. Interdependencies with other organisations, healthcare professionals of varying disciplines and patients are just some examples how relationships between organisations and people leads to a complex information map, asymmetry and potentially conflicting goals.

Performance assessment frameworks are used to monitor healthcare systems, but many are variable quality and coverage is often not comprehensive or adequately balanced (Smith, 2002). Authors argue that performing well should mean improving quality, not simply productivity (Dixon, 2000). Strict reliance on measuring quantitative data contained in administrative datasets can only assess care elements that are consistently and reliably recorded. Some argue that data collected for administrative or financial purposes will not meet quality assessment data requirements (Campbell et al., 2000). As well as the more traditional performance criteria such as: adherence to strict budgets, maximising patient through-put and waiting times reduction for elective surgery, a broader view of what constitutes health system performance is increasingly seen as important, including, for example, patient satisfaction and clinical quality. However, a challenge to implementing this wider view is the ability to integrate top-down performance management (standards, priorities and accountability) with clinical network systems (professional concern with clinical quality, patient focus, peer review and continuous improvement) (Smith, 2002).

While there are many reasons to promote performance management there are counterarguments such as: distortion, exclusion, misinterpretation and data manipulation along with high transaction costs and employee demoralisation (Talbot, 2005). Poor data quality and comparability, differing priorities or perspectives among stakeholders, insufficient expertise and insufficient linkage with subsequent action (Sheldon, 2005) exemplify how performance management can result in unintended consequences. There is little consensus on performance measurement' simportance or management within healthcare and evidence supporting its effectiveness is equivocal and contested.

\section{NHS context}


The NHS in England has undergone structural change since 2010, following the first coalition government since 1945. The White Paper: Equity and Excellence - Liberating the NHS (DH, 2010) outlined fundamental reforms to the NHS - devolving commissioning budgets to local areas and replacing primary care trusts (PCTs) with smaller clinically led clinical commissioning groups (CCGs) and abolishing strategic health authorities (SHAs), the bodies responsible for ensuring that PCTs performed effectively, and the layer between them and the Department of Health. The following three years saw these plans put into action, with responsibilities and functions allocated differently across various organisations including CCGs, NHS England, Public Health England, local authorities and commissioning support units (CSUs). The political debate highlighted the difficulties managing a complex system at a time when cutting management cost remained a national priority. Despite changes in organisations and structures, performance management through healthcare commissioners continues to be an important assurance and accountability elements.

Various performance measures are used at a national level to assess English primary care organisation/CCG performance, including referral to treatment cancer and $\mathrm{A} \& \mathrm{E}$ targets, and waiting times. The Quality and Outcomes Framework (QOF) is the performance framework that helps to form the General Medical Services (GMS) contract for general practices and was introduced on 1 April 2004. The QOF rewards practices for providing quality care with financial resources, and helps to fund further improvements in clinical care.

| The empirical data on which this paper is based (Rogan 2 2013) was gathered when SHAs and PCTs still existed. Strategic health authority staff were responsible for agreeing the organisation's strategy and monitoring performance against financial, quality and other targets. Improving public health and reducing health inequalities were also important strategic objectives. Primary care trusts were the local NHS commissioners who had ultimate accountability for commissioning health services within the local area and for ensuring that the local health system worked towards improving the population's health and well-being.

Primary care trust staff were responsible for identifying current and future local health needs, working with clinicians, public and other stakeholders, and had responsibility for seeking views and input from clinicians and across the community to inform the development of strategic priorities for healthcare in the local area. Primary care trust staff were encouraged to work with clinicians in reviewing services or designing new service models and had responsibility to ensure that the right infrastructure was in place to enable this to happen. These commissioning relationships are similar in the current structures and relationships in the NHS in England, where CCG managers are the commissioners and accountable to NHSE

| for performance management. The research on which this paper is based (Rogan, 2013) was carried out at a time when the current structures had been announced but not put in place and so some reference is made to these throughout.

\section{Principal-agent theory}

Our purpose is to explore whether principal-agent theory can be used to better understand primary care performance management. Principal-agent theory is described as a dilemma where one party (the principal) needs another party (the agent) to deliver the first party's objectives, although the principal cannot fully control or even observe the agent's activity (NAO, 2008). It has its origins in economic theory (Smith, 1776). The principal-agent theory challenge has been described as:

The central dilemma being that the contractor or agent has an informational advantage and different objectives to the employer or principal. The agent's objectives are often to maximise its own profits, rather than to produce the maximum quality or quantity of the good the principal desires (NAO, 2008, p. 6). 
The principal-agent problem is often clear in contractual agreements that are written within an information asymmetry context (i.e., informational advantage), uncertainty and risk where principals can never hope to completely check an agent's performance. This may arise in the public sector between organisations, teams and individuals within a delivery chain. Where multiple stakeholders (principals) exist, such as in the public sector, priorities may not be fully aligned between all parties, giving rise to potentially conflicting objectives. This is in contrast to the private sector where generally owner interests are focused on the single value maximization objective (Dixit, 2002). Public sector managers are often expected to simultaneously achieve cost-effectiveness and equity. The relationship is underpinned by principal and agent's self-interest.

The growing emphasis on primary care performance management highlights the importance of understanding and exploring this concept. In our research, principal-agent theory has been used to explain the relationship between commissioners (principals) and clinicians or GPs (agents) as healthcare providers. Its application enables a better understanding of the importance, use and problems associated with performance management by managers and clinicians in the English NHS from a primary care perspective. An outline how the principal-agent theoretical framework is applied in this research is provided in Figure I. Clinicians will be referred to as agents throughout and commissioners (SHA/PCT managers) as principals.

\section{Figure 1 here}




\begin{abstract}
Methods
Qualitative methods were used within a single case study framework to investigate the ways in which primary care performance is understood from the principals and agents' perspectives.
\end{abstract}

\title{
Participants
}

The research was carried out in one SHA, one PCT and 12 general practices in the same geographical area in England. General practices were selected using various information to ensure a broad response:

1. Practice size (registered patients)

2. Ethnicity (\% South Asian) - because the area where the research was carried out has some areas where there South Asian patients are concentrated.

3. Deprivation (based on low income score index - LISI)

4. Clinical Performance (combined clinical productivity performance indicators) - to explore performance management understanding, awareness and variation in primary care during the interviews using sample performance data on clinical indicators.

5. Prescribing Performance (combined prescribing productivity indicators) - to explore performance management understanding, awareness and variation in primary care during the interviews using sample performance data on prescribing.

Primary care trust executive and non-executive directors were selected based on their corporate responsibility for organisational performance. Senior managers were selected based on their role and involvement in managing primary care performance in relation to productivity performance indicators. All six executive and non-executive directors invited to participate from the PCT accepted the invitation. The SHA directors and associate directors were selected based on their role and involvement in primary care performance management in relation to productivity performance indicators. Of four invitees, three accepted and one delegated responsibility to an associate director who led on performance management in primary care.

\section{Data collection and analysis}

The interview schedule was developed using the findings from relevant literature and informal interviews. The use of informal interviews allowed the exploration of the face validity of questions and terminology, prior to the formal interviews (Campbell et al., 2002). Throughout the process, consideration was given to the underlying assumptions of the principal-agent theoretical framework and research objectives, enabling links between the results and broader theoretical framework as appropriate to case study research (Yin, 1989). . The interview schedule covered performance management and inter-organisational relationships; performance management information, barriers to performance management and incentives and rewards.

Twenty-six participants were interviewed: ten GPs, two practice managers, six PCT executive directors, one PCT non-executive director, four SHA directors and three senior managers. Each interview lasted on average 45 minutes and was held on NHS premises in a private and confidential setting. Interviews were audio-recorded and transcribed to increase reliability. Following each interview, a consent form along with a follow up letter was sent to individuals who had participated in the study expressing thanks for their contribution and offering the opportunity to ask questions or contact the researcher if there was a desire to provide further information. 
Interviews were transcribed, coded and organised into themes with the support of NVIVO 8 computer software. Matrix analysis techniques were used to summarise and theme data accordingly and an iterative process was employed to ensure reliability of coding (Saldana, 2012). These techniques were selected owing to the amount of data requiring analysis and the ability to view wide ranging information at one time. Data were analysed using recurrent themes across responses from different disciplines and comments as well as specific quotes which although infrequent, contributed richness and depth of the findings.

\section{Findings}

The findings cover understanding performance management, performance data in primary care and barriers to performance management, which are then synthesised in the discussion to show how the principal-agent framework helps understanding. Principal is represented by the managers (PCT or SHA) and agent is represented by clinicians (general practitioners))

\section{Understanding performance management}

Most participants from all backgrounds viewed performance measurement as data collection for comparison and bench-marking purposes. There was a view that although measurement needs to come first, quantitative metrics often have little or no meaning in isolation. With respect to performance management, most participants across the various disciplines described the term performance management as: using data to promote actions or change, to instil an improvement, or to achieve desired objectives. One director referred to performance management as: measurement with a purpose. There was also a sense that in contrast to performance measurement, which was considered a quantitative approach, performance management adopted a more qualitative approach. General practitioners tended to describe performance management as comparison with peers or benchmarking, while managers generally believed that performance management was about achieving quality, standards and objectives. However, interviewees from various backgrounds made reference to the need to account for softer performance intelligence and measureable factors:

... softer measures, such as staff training and staff turnover, need to be considered as much as harder measures as this can have just as important effect on quality of patient care.

... there needs to be some audit of proxy measures across the whole pathway rather than simply counting the numbers.

Although outcomes were mentioned by clinicians (as agents) and managers (as the principal), there was a general consensus across both principals and agents that current systems and processes tend to focus only on numbers (measurement) rather than taking a holistic approach that would more appropriately reflect performance.

\section{Performance measurement and management}

All respondents indicated that there is more focus on NHS performance measurement than performance management. One GP felt that performance management was poor:

Performance management is not done well in primary care - we get lots of statistics and figures thrown at us and we go away and do our own management internally within the practice but in terms of external management - I don't think there is much going on 
Most participants believed that the NHS focused more on performance measurement than performance management and the terms are often used interchangeably. Reasons offered to explain this from several GPs and managers were:

... measurement is easier

... there is a focus on things that are easy to measure rather than what's important ... management is more challenging

There was a view from SHA directors (the principal) that often measures are not valid, research-based or related to outcomes. Concern was expressed by SHA and some PCT directors about how misunderstanding can result in jumping to the wrong conclusions. One GP provided an example how referral rates could easily be misinterpreted:

High or low referrals may not be right or wrong and can often be explained by a variety of factors such as: lack of confidence, incompetence, time constraints, special interest, and morbidity levels etc.

Other barriers and difficulties with primary care performance indicators were highlighted:

a) Unsophisticated and poor understanding of measures and terminology.

b) There were problems with timescales associated with outcome measures.

c) There were too many indicators and too much time spent collecting data: feeding the beast, playing the game, chasing targets and not enough time spent using the data to improve patient care.

Clinicians found it difficult to find time to engage with performance management outside clinical commitments.

\section{The principal-agent relationship}

Managers generally believed there was a tension between managers as the principal and clinicians as agents, whereas fewer clinicians held this view. There was a belief by the principal that conflict exists because clinicians are not trained as managers and tend to focus on outcomes at an individual level whereas managers tend to place more attention on outcomes at a population level. The principals recognised the difficulty attaining an adequate mix of the two perspectives. Clinicians (as the agent) took the view that managers and clinicians viewed performance management from different perspectives and misunderstanding and non-acknowledgment of the opposing viewpoint often leads to mistrust between the two parties. The principals generally believed that a hierarchical relationship exists between managers and clinicians with clinicians holding what was described as professional superiority. Some management respondents felt it was difficult to challenge clinicians' performance:

.... a manager is subservient to the clinician because they cannot exercise enough clout over a GP. This isn't how it should be ...

... the medical profession has a natural professional superiority through academic and professional qualifications, which implies a higher level of attainment.

The only performance management mentioned by clinicians as the agent as relevant to them was the Quality and Outcomes Framework (QOF), and the local and national enhanced 
services; both associated with significant financial rewards. Clinicians (agents) generally believed that accountability and autonomy should go hand-in-hand. Most described accountability as being answerable and the term autonomy as devolved power or having the freedom to act. Clinicians viewed accountability in the patient context whereas managers (the principal) referred to accountability as being accountable to the tax payer and having the responsibility for public money. Reference was made by some management participants to the (at the time) future NHS changes regarding devolving budgets and clinically led commissioning arrangements through CCGs. There was a perception that new responsibilities and accountabilities by clinicians as the agents weren't recognised. There were concerns about them taking on significant responsibilities in CCGs equivalent to PCT chief executives.

... it's impossible to have someone not employed by an organisation being held to account with corporate responsibility especially when they have a vested interest in driving their bottom line.

Agents made reference to micro-managing clinicians as being counter-productive, stifling innovation and deterring progress that would ultimately damage the profession in the long term. However, there was also a view by one GP that there ought to be greater accountability and less autonomy applied to poor performing practitioners; both financially and clinically. Both principals and agents agreed there was a professional tension between clinicians and managers that contributes to disengagement with performance management:

As clinicians we tend to focus on patient outcomes and retaining professional autonomy whilst managers want to control.

Principals in general did not feel that clinicians as agents were engaged with performance management as this is not something in which they are trained. Others believed that performance management was often seen as threatening to clinicians who were sceptical of performance measures especially when the measures relating to their respective practices did not fall within an acceptable range from the average when they would seek ways to discredit the data. There was a variable response to the perceived clinical disengagement with performance management. Principals in particular believed that a few self-promoting clinicians, often those who had taken on PCT leadership and clinical roles tended to represent the professional body at large that always risks not engaging the right clinicians. There was a belief by agents that managers as the principal were more engaged than clinicians with performance management and that the question should really be:

Is performance management being used for the right purpose?

\section{Performance data in primary care}

Examples were cited during interviews from the various disciplines on how performance data was used in primary care to promote change. More agents than principals cited using prescribing data to promote a change in prescribing behaviour. Principals referred to pathway re-design and referral data whereas agents cited QOF data to improve patient outcomes. Using clinical audit to improve outcomes for patients through revising the end-of-life care pathway was one example where performance data resulted in change. Practice review meetings was another example where performance information had been used to promote improvements through reviewing appointment systems and improving access. Agents referred to the Quality and Outcomes Framework (QOF) when asked about current performance indicators used to assess primary care performance. Agents generally believed 
Agents mentioned QOF indicator considered poor quality-measures owing to their subjective nature:

... Patient experience questionnaire is very questionable. It is very subjective, unreliable and involves such a small number of patients within a practice. It really is not a meaningful performance measure.

Reference was made to inappropriate strategic behaviour potentially resulting in unintended consequences:

... When developing performance frameworks, there is often a lack of recognition that people will game the system. Similar to restricting certain treatments by setting criteria, but as soon as that criteria becomes common knowledge an individuals' eligibility changes in order to meet the criteria.

... Twenty-four/forty-eight primary care access targets simply made GPs restrict booking and access in order to meet the target. Thus the desired outcome was not achieved and resulted in poor patient satisfaction.

Although principals and agents generally believed that incentivising performance measures, such as productivity performance indicators, could change behaviour, there was a view that such indicators (aside from those already included in QOF, regarded as clinical indicators) should not become a mandatory contractual obligation. Some respondents believed that incorporating such measures into QOF would lead to perverse behaviour and unintended consequences where practice staff could game the system to their benefit and at patient care expense.

There would be concerns over how the measures could be incorporated safely due to potential associated perverse behaviour. For example, if average referrals over the year is looking high, patients may suffer if not referred appropriately simply because of the need to hit a target and receive an incentive ...

... to incentivise 'to avoid certain things' could be the start of patients being rationed by the back door.

... this will lead to 'gaming' in the system. How can I get my maximum points? Or how can I fulfil my contractual obligations?

With respect to referral targets, agents referred to putting clinicians in a difficult position causing a potential conflict as the patient's advocate. Value alignment was raised by a principal as being key to aligning objectives: 
... the contract is only the formality, it's the values alignment you need. You don't have to worry too much about what it says in the contract. If everybody is agreed that they want to do it, you almost never go back to the contract. You need it in the contract when somebody doesn't want to do it actually.

Agents criticised the current performance management and related measures:

.... most indicators are designed with different functions in mind - the question should be: are the indicators really achieving their aims? The other question is: is it a good use of public money? The new GP contract resulted in a huge amount of public money being thrown at trying to improve standards of care which were already being achieved!

... indicators are often developed as a knee-jerk reaction to a situation. Performance measurement has gone too far ... it should be tied into professional re-validation ...

A principal commented on the difficulty making comparisons in health care:

Performance management can be helpful if you are comparing 'like-with-like' but the problem with health is the range of environmental factors, which are not considered. Crude data doesn't take into consideration these factors.

\section{Discussion}

Our findings show that performance management is influenced by understanding performance management, the systems used and the principal-agent relationship, which influence goal alignment and performance.

\section{Understanding performance management}

Goal alignment depends on the degree to which a common understanding and clarity of meaning can be reached across all key stakeholders. The findings suggest there is confusion between the terms performance measurement and performance management and they are often used interchangeably in the NHS. The two are interpreted differently among different professional groups. The confusion and different interpretation by principals and agents suggests different professional groups have different beliefs of what constitutes performance management and performance measurement. Although principal-agent theory suggests goal alignment can be achieved through shared objectives, this research shows that it is not happening in practice. In the NHS, varied and multiple relationships exist between professionals that result in a complex web of information asymmetry and self-interest that need to be balanced against the desired objectives. Our findings suggest that goal alignment may only ever be achieved in part, owing to factors such as professional background and relationships between the principal and agent. The degree to which goal alignment is achieved depends commonality and agreement on understanding what constitutes performance management and trust between principal and agent. This may be increased once clinical staff join the commissioning process; i.e., take the principal role through involvement in CCGs - possible area for further research using the principal-agent framework.

Systems used for performance management

1. Qualitative measures and soft intelligence. Where qualitative measures, soft intelligence and tangible metrics are used as a performance management system, goal alignment 
needs to apply to all. There was agreement across both principals and agents, who believed that NHS staff tends to focus on things that are easy to measure rather than managing what is important. This may be because performance management is more challenging than simply measuring predetermined targets. Findings suggest that soft performance intelligence, such as: training, multidisciplinary teamwork, communication and shared vision may be as high a priority as the harder, more tangible metrics. All parties appear to agree the need for wider ranging measures.

2. Influences on system design and management. Goal alignment may be achieved by principals influencing local clinical engagement and ownership with clinicians as agents, and on agreeing primary care performance indicators with policy makers. Little reference to QOF by managers (a framework they did not design or monitor) suggests this was not a priority, or that outcomes were being delivered to an adequate standard irrespective of local performance management techniques. This may be because the framework forms part of a nationally negotiated contract and so there is little influence that can be applied locally to affect how it is delivered. Another explanation might be that metrics included within the framework are so well resourced (financial incentives) that adequate standards are being achieved irrespective of the meaning or quality. Findings about the QOF and the financial rewards associated with the framework showed that there were QOF indicators considered by some clinicians as poor quality-measures. These could lead to poorer outcomes for patients, yet practices continue to be incentivised for achieving such targets. Some principals and agents believed that indicators were excessive, which led to a chasing targets culture rather than improving service quality.

3. Accurate, responsive and timely data. The data used for performance management must be accurate, up to date, and responsive to changes over time, and adequately explained prior to being used. The findings showed that misunderstanding and poor datainterpretation can lead to inaccurate conclusions and erroneous decisions. This was a common concern from both principal and agent.

\section{The principal-agent relationship}

1. Trust. The trust between principal and agent depends on the degree to which information asymmetry can be overcome and goal alignment achieved. This involves addressing professional superiority. At a practice level, the perceived hierarchical relationship between managers as the principal and clinicians as agents could act as a barrier to improving performance and achieving goal alignment. There was a belief by the principal that, clinicians as agents focussed on outcomes at an individual level and have difficulty understanding population health economics. Clinicians accepted being challenged on their performance by an expert in that particular field or a peer rather than a general manager.

2. Autonomy and accountability. Goal alignment depends on principals and agents supporting the overall vision and objectives, and ensuring the right balance is struck between accountability and responsibility, and the flexibility to innovate. Principals viewed accountability as being to the taxpayer compared with the agents or clinicians who referred to accountability as being to their patients. Managers believed there should be greater accountability to the tax payer whereas clinicians believed that less micro-management improves performance and innovation. This conflict is reported in the literature as the need to integrate tangible performance management such as standards, priorities and accountability with clinical network soft intelligence systems, professional concern, patient focus, peer review and continuous improvement (Smith, 2004). 


\begin{abstract}
Although there appeared to be a variable response by clinicians with performance management, Principals generally believed that a few clinicians who had taken on PCT leadership and clinical roles tended to represent the professional body at large. This always risks not engaging the right clinicians. Based on our findings, an adapted principal-agent theory, when applied to primary care, has been developed (Figure 2).
\end{abstract}

\title{
Figure 2 here
}

\section{Conclusion}

The principal-agent theoretical framework can be used to better understanding primary care performance management. Exploring two Information asymmetry and goal alignment assumptions helps to understand and explain the empirical findings. Complex professional relationships and inter-dependencies within the NHS that influence goal alignment suggests that goal alignment is unlikely to be fully achieved. However, it is possible that greater alignment will be achieved by involving clinicians in commissioning and general practice performance management following the recent NHS reforms. The degree to which a common understanding and clearer meaning can be reached among principals and agents will affect performance. Consistently interpreting objectives at all levels with adequate communication throughout the organisation will affect performance and subsequent goal alignment. This will remain a challenge within the NHS owing to professional backgrounds and training.

As well as tangible metrics, valued qualitative measures and soft intelligence must be a performance management system if goal alignment is to be achieved. The influence of managers as the principal over local clinical engagement and local ownership is a crucial element to improving goal alignment. Incentives and rewards aligned to strategic objectives that cannot lead to inadvertent behaviour and unintended consequences is also important. Achieving goal alignment and improving performance is an important relationship between the principal and agent, and in particular the trust between them, which will affect many other dimensions that influence information asymmetry and goal alignment. These include: stakeholders' ability to overcome the divide between managers as the principal and clinicians as agents; the level at which principals and agents agree with the overall vision and objectives; attaining the right balance between financial and clinical accountability with clinical autonomy and the flexibility to innovate; and ensuring information is: accurate, up to date, responsive and adequately explained prior to use or release into the public domain.

\section{References}

Adair, C.E., Simpson, L., Birdsell J.M., Omelchuk, K., Casebeer, A.L., Gardiner, H.P., Newman, S., Beckie, A., Clelland, S., Hayden, K.A., Beausejour, P. (2003), 'Performance measurement systems in health and mental health services: models, practices and effectiveness', A State of the Science Review, Alberta Heritage Foundation for Medical Research. 
Campbell, S.M., Roland, M.O., Buetow, A.S. (2000), 'Defining quality of care', Social Science and Medicine, Vol. 51 No. 11, pp. 1611-1625.

Campbell, S.M., Braspenning, J., Hutchinson, A., Marshall, M. (2002), 'Research methods used in developing and applying quality indicators in primary care', Quality and Safety in Health Care, Vol. 11 No. 4, pp. 358-364.

Carman, J.G., Fredericks, K.A., (2010), 'Evaluation capacity and non-profit organizations: Is the glass half-empty or half-full?', American Journal of Evaluation, Vol. 31 No. 1, pp. 84-104.

Department of Health. (2010), 'Equity and Excellence: Liberating the NHS', Department of Health, London.

Dixit, A., (2002), 'Incentives and Organizations in the Public Sector: An Interpretive Review', Journal of Human Resources, Vol. 37 No. 4, pp. 696-727.

Dixon, J. (2000), 'Modernising the NHS - Performance and Productivity', British Medical Journal, Vol, Vol. 320 No. 1462, pp. 1462-1464.

Lingle, J.H., and Schiemann, W.A. (1996), 'From balanced scorecard to strategy gauge. Is measurement worth it?', Management Review, Vol. 85 No. 3. pp. 56-62.

Neely, A. (1999), 'The performance measurement revolution: why now and what next?' International Journal of Operations and Production Management, Vol. 19 No. 2, pp. 205-28.

Propper, C., and Wilson D. (2003), 'The Use and Usefulness of Performance Measures in the Public Sector', Oxford Review of Economic Policy, Vol. 19 No. 2, pp. 250-267.

Radnor, Z. and McGuire, M. (2004), 'Performance management in the public sector: fact or fiction?', International Journal of Productivity and Performance Management, Vol. 53 No.3, pp. 245-260.

Rogan, L. (2013), 'Performance Management in Primary Care. How can the Principal-Agent Theoretical Framework be used to attain a better understanding of performance management in primary care?' PhD Thesis, University of Manchester.

Ryan, R.J., Scapens, R.W., Theobald M. (2002), Research Methods and Methodology in Accounting and Finance ( $2^{\text {nd }}$ ed.) London: Thomson Learning.

Saldana, J. (2012), The coding manual for qualitative researchers $\left(2^{\text {nd }} e d.\right)$, Sage, London

Sheldon, T.A. (2005), 'The healthcare quality measurement industry: time to slow the juggernaut?' Quality and Safety in Health Care, Vol. 14 No. 1, pp. 3-4.

Smith, A. (1776), 'Incentives in Economic Thought', In Laffont, J.J., and Martimort, D., (2001), The Theory of Incentives I: The Principal-Agent Model, Princeton University Press, Oxfordshire, pp. 11-36

Smith, P (2002), 'Performance Management In British Health Care: Will It Deliver?' Health Affairs, Vol 21 No. 3, pp.103-114.

Smith, J.A., Mays, N., Dixon J., (2004), A Review of the Effectiveness of Primary Care-led Commissioning and its place in the UK NHS. London: The Health Foundation.

Talbot, C. (2005), 'Performance Management', In The Oxford Handbook of Public Management, Oxford University Press, Oxford, pp. 491-517.

The National Audit Office (NAO)., by Deloitte (2008), 'The use of sanctions and rewards in the public sector.' SLS Print, London.

Yin, R.K. (1989), Case Study Research. Design and Methods, Sage Publications, Newbury Park CA. 
Figure 1: The principal-agent theoretical framework and its application

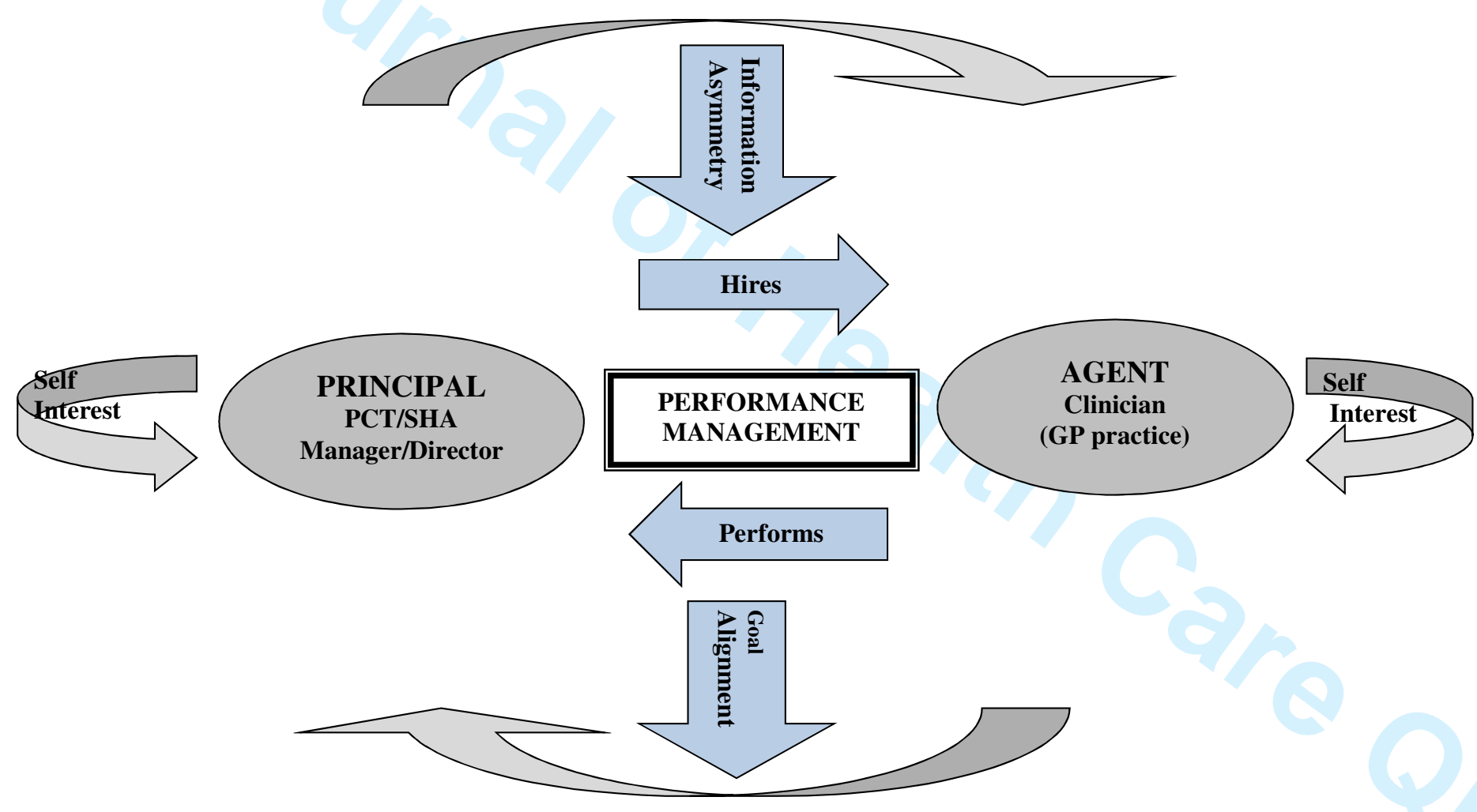


Figure 2: Agency theory applied to primary healthcare

\begin{tabular}{|c|c|c|}
\hline \multicolumn{3}{|c|}{$\begin{array}{l}\text { PERFORMANCE MANAGEMENT } \\
\text { Is influenced by: }\end{array}$} \\
\hline $\begin{array}{l}\text { Understanding } \\
\text { Performance } \\
\text { Management }\end{array}$ & $\begin{array}{c}\text { Systems used for } \\
\text { Performance Management }\end{array}$ & $\begin{array}{l}\text { Relationship between } \\
\text { Principal and Agent }\end{array}$ \\
\hline $\begin{array}{l}\text { Common } \\
\text { understanding and } \\
\text { consistently } \\
\text { interpreting objectives } \\
\text { at all levels throughout } \\
\text { the organisation } \\
\text { Clear strategic } \\
\text { direction from policy } \\
\text { makers }\end{array}$ & $\begin{array}{l}\text { Qualitative measures and soft } \\
\text { intelligence as well as tangible } \\
\text { metrics } \\
\text { Local clinical engagement and } \\
\text { ownership } \\
\text { Information being: accurate, } \\
\text { up to date, responsive and } \\
\text { adequately explained prior to } \\
\text { public release. }\end{array}$ & $\begin{array}{l}\text { Trust between principal } \\
\text { and agent } \\
\text { Ability to overcome } \\
\text { information asymmetry } \\
\text { between principal and } \\
\text { agent } \\
\text { Getting the correct balance } \\
\text { between autonomy and } \\
\text { flexibility to innovate with } \\
\text { accountability } \\
\text { Overcome inadvertently } \\
\text { using incentives and } \\
\text { potential unintended } \\
\text { consequences }\end{array}$ \\
\hline
\end{tabular}

Goal alignment and improved performance depends on achieving these factors

\section{IMPROVED PERFORMANCE}

